\title{
Research on the Current Situation, Problems and Countermeasures of SMEs Salary Management
}

\author{
Lei Zhou' \\ ${ }^{1}$ Nanchang Institute of Science \& Technology, Nanchang, Jiangxi, 330000
}

Keywords: current situation; problems and countermeasures; SMEs

\begin{abstract}
Small and medium-sized enterprises are an important part of the market economy and also play an important role in promoting the economic development of the country. With the deepening development of market economy, SMEs also encountered certain difficulties. Salary management is an important guarantee for the development of enterprises. However, there are some problems in the salary management of SMEs. The unscientific position analysis, the imperfect salary management system and the lack of long-term development in enterprises are the problems in the current salary management of SMEs, and corresponding solutions to these problems are put forward in the hope to provide some reference for the salary management.
\end{abstract}

\section{Introduction}

The significant increase in the number of SMEs has become an indispensable part of our economic development and has been developing very rapidly. SMEs have a relatively simple starting point for initial economic requirements, relatively simple requirements for approval and management, and a high degree of economic vitality. At present, they have become the main body of China's economic development. While their own development, SMEs also promote the development and progress of China's economy, but also more effectively improve the local labor force employment situation. The development of SMEs has been able to significantly affect the local economy and employment of personnel.

\section{The Status of Employee Salary Management in SMEs}

After analyzing the information of many small and medium-sized enterprises in the aspect of employee compensation management in our country, we can find that almost all the control of the working cost in the management of SMEs is based on the personal experience of the leader, that is to say SMEs in China pay attention to the management of employee personal experience with emphasis on the characteristics of SMEs management generally small, and the organization is relatively loose, a lot of practical corporate decision-making through the leadership of all the guidance and delivery has become inevitable. In terms of remuneration control, whether SMEs choose to control their remuneration or take control of their remuneration is determined by their leadership depending on their personal experience. Questions such as which department the employee remuneration management is to be implemented, how to implement it, what measures are taken and so on All depend on the level of individual's understanding of the issue [1].

Looking at the majority of SMEs in our country, especially small and medium-sized SMEs, their specific work on employee compensation management is arbitrary and strong is a more prominent feature. I collected some SMEs related management activities and found that, Most of the SME employee compensation management of the main work is generally led by the SME leaders assigned to the accounting department to complete this level mainly to control the gray remuneration of employee pay expenses. However, SMEs in the business process and other staff remuneration expenses related However, there is a lack of management and restraint in the link. For example, the salary increase part of the employees and the employee salary incentive part about the year-end are very arbitrary [2].

Another prominent feature in the management of employee remuneration is that employees' 
remuneration management within SMEs is mostly handled as an independent issue. Employee remuneration management is entrusted by the leaders of SMEs to assign accounting departments to handle daily financial accounting work at the same time pay attention to the strict implementation of employee payroll work, to minimize unnecessary gray spending, in order to control the overall SME payroll expenses. According to the accounting department staff is serious or not the leadership of the implementation of this requirement can not be considered, can not be held accountable The concrete effect of its implementation can only be sustained by the accounting department's own sense of enlightenment and work sense of responsibility. Although leaders of SMEs try to promote SME employee compensation management from idea, the actual effect is that they can not control [3].

\section{The Problems of Employee Salary Management in SMEs}

Although the small and medium-sized enterprises are not large-scale, there are also some post division of labor. Different positions are responsible for the content is often different, and its contribution to the enterprise is also different, but not reflected in the specific salary Obvious difference. The main reason for the small difference in salary is that SMEs lack scientific analysis of positions in management and do not conduct an accurate assessment of the economic benefits of different jobs, thus making it difficult to distinguish the value of positions within the enterprise and the function of the SMEs There is no obvious difference between the big positions and those ordinary positions in the remuneration package, which also makes many employees do not receive due rewards after exerting a great effort, which further affects the enthusiasm of the employees. This is also the further development of the SMEs Played no small role in the control.

Many enterprises pay management are often used both basic salary and performance pay, which is more fixed basic salary, performance pay changes are great. Many small and medium-sized enterprises in the management of performance pay there is a big problem, performance pay affects the enthusiasm of employees, especially for those with low qualifications, lack of work experience and short working hours, performance work is its efforts One of the motivation of work. Many small and medium-sized enterprises pay remuneration method is relatively backward, they often based on their qualifications, work experience and working years to develop different remuneration, and once the implementation of a specific method of remuneration in a long period of time is difficult to change. Under normal circumstances, many SMEs will be based on staff qualifications and job-level compensation for pay, ignoring the performance appraisal in the actual work of staff an important role, which not only affects the normal operation of enterprises but also easily reduce the work of employees Positivity. SMEs rely too much on the basic salary and performance salary in their salary management. The benefits they give employees are very few. Welfare benefits include many kinds. They play a very important role in encouraging employees to work hard. On the one hand, economic reasons, on the other hand, are due to the fact that the management of SMEs does not pay enough attention to the benefits. As a result, many employees are denied some benefits and negative psychology, thereby affecting their long-term development. At the same time, SMEs pay management system is also a problem, many SMEs have too much power of the leadership or managers, often in the payroll management by virtue of subjective guess the level of pay and salary distribution. In addition SMEs lack of sound internal compensation management agencies, even if the existence of compensation management departments are often non-existent, the decision-making will be subject to the leadership of the order [4].

\section{Measures to Improve the Level of Salary Management in SMEs}

Mentioned above, SME pay management in the obvious problem is the lack of scientific job analysis, no difference in remuneration to reduce the staff's enthusiasm for work, there have been difficulties in business development, so in response to this problem, SMEs should be carried out Scientific job analysis, develop a set of scientific and reasonable salary distribution mechanism. Scientific job analysis needs to have a clear understanding of the nature and function of different 
jobs, calculate the economic value that it creates for the enterprise within a certain period of time through specific digital studies, and then make the corresponding Remuneration, in order to create a fair internal environment for the company, create effective disclosure of information about the different remuneration packages within the enterprise so that some employees will be prevented from being unbalanced. Only by analyzing the scientific posts and formulating a scientific and reasonable salary mechanism can we mobilize the enthusiasm of our employees so that ordinary employees can strive for higher remuneration and thus promote the rapid development of SMEs.

The above mentioned in the scientific job analysis and job evaluation based on the development of different salary levels, job positions in different positions after accurate evaluation of the performance of a reasonable connection. Many SMEs often neglect the important role of performance appraisal, making many employees with low basic wages unable to work hard to obtain satisfactory remuneration. SMEs can use the KPI, BSC and other scientific statistical methods for performance appraisal, and only use scientific assessment methods to ensure fair performance appraisal. As before has done a job analysis and job evaluation, so in the performance appraisal can be based on the different nature of the work of employees and the contribution made to the development of enterprises to carry out a differential assessment. Although the basic salary can not be easily changed, the pay for performance can be managed according to individual performance. Therefore, making a performance evaluation and management plan with some differences can arouse the enthusiasm of employees. SMEs should learn how to flexibly use performance appraisal methods in their salary management, formulate a scientific and reasonable performance appraisal system according to different positions and their different contributions to the development of the enterprise, and closely link the performance appraisal with the management of individual pay. Through the performance appraisal of the staff of a clear division of labor, so do more work, personal performance and team performance and pay management closely linked to the flexible compensation management system. Use the performance appraisal to balance the differences in remuneration among different work positions within the enterprise and arouse the enthusiasm of all the employees in the enterprise so that they can expect to obtain higher salaries especially through their efforts. At the same time in order to retain talent, SMEs should conduct an adequate market research on the entire market environment, the other companies how to conduct a pay management and performance appraisal should have an accurate understanding, and then based on the entire market pay, the average performance appraisal standards to develop a payroll management system within the enterprise. Perfecting the benefits is also an important part of improving the remuneration management system. SMEs can provide employees with various types of benefits such as holiday gifts, year-end bonuses and other material rewards as effective ways to improve the system of benefits, as well as an honorary title is a kind of corporate welfare, which can mobilize the enthusiasm of employees. To improve the remuneration management system, we must improve the remuneration management department. We can not rely solely on the decision-making of the leadership. We must comprehensively consider various factors, especially market analysis and business analysis, which are more important reference for the system of remuneration management [5].

SMEs in the pay grades based on the reference is too simple to ignore the important role of performance pay, so in order to better improve the compensation management mechanism for SMEs should know how to make flexible use of post-measurement methods. Small and medium-sized enterprises should adopt the scientific method of salary measurement actively. They should not divide the remuneration according to the employees' qualifications and work positions. In the course of remuneration management, the working hours, income from enterprises and extra expenses can be included in the scope of remuneration measurement, further in the corporate dividends, year-end bonuses and benefits reflected, so that we can create a fair and just, more work and more business atmosphere. In addition, pay management, especially the payroll should pay attention to the role of outstanding employees to play, taking into account the interests of most people can not just to meet the interests of some people and the use of unfair assessment methods. 


\section{Conclusion}

At present, in the rapid economic development, human resources have become an important factor in the development of enterprises. Most enterprises have placed their human resources in the first place of business management. Therefore, more and more enterprises shift the focus of competition to human resources. Payroll management is an important factor in human resource management. Through effective salary management, it not only provides a stable life for employees, but also increases employees 'enthusiasm for work and loyalty to the enterprise, stabilizes employees' sense of belonging, the overall job satisfaction, thereby increasing the effectiveness of enterprises and profits. Therefore, sound remuneration management has played an important role in promoting and helping the development of small and medium-sized enterprises.

\section{References}

[1] Ma Jing, Xu Huizhen. SMEs compensation management issues and optimization measures [J]. China business, 2012, (18): 82-83.

[2] Geng Xinnan, Qiao Ruizhong On the SME human resources compensation management problems and countermeasures [J] Hong Kong and Macao Economy, 2015, (14): 80-81.

[3] Xu Qiaoling. China's SME pay management problems and countermeasures [J]. Economist, 2014, (10): 213-214.

[4] He Lixia. SMEs pay management problems and countermeasures [J]. Enterprise Reform and Management, 2016 (12): 80-81.

[5] Zhang Xiaoxin, Liu Bin. Analysis of SME pay management problems and countermeasures [J] Science and Technology Outlook, 2017,27 (10). 